Review

\title{
Advancement in Electrospun Nanofibrous Membranes Modification and Their Application in Water Treatment
}

Shaik Anwar Ahamed Nabeela Nasreen ${ }^{1, *}$, Subramanian Sundarrajan ${ }^{2, *}$, Syed Abdulrahim Syed Nizar ${ }^{1}$, Ramalingam Balamurugan ${ }^{1}$ and Seeram Ramakrishna ${ }^{1,2, *}$

1 NUS Nanoscience and Nanotechnology Institute, National University of Singapore, 2 Engineering Drive 3, 117581, Singapore

2 Department of Mechanical Engineering, National University of Singapore, 2 Engineering Drive 3, 117575, Singapore

* Authors to whom correspondence should be addressed;

E-Mails: saanabeela@gmail.com (S.A.A.N.N.); sundarnus1@gmail.com (S.S.); seeram@nus.edu.sg (S.R.); Tel.: +65-6516-4272 (S.R.); Fax: +65-6773-0339 (S.R.).

Received: 3 September 2013 / Accepted: 13 September 2013 / Published: 30 September 2013

\begin{abstract}
Water, among the most valuable natural resources available on earth, is under serious threat as a result of undesirable human activities: for example, marine dumping, atmospheric deposition, domestic, industrial and agricultural practices. Optimizing current methodologies and developing new and effective techniques to remove contaminants from water is the current focus of interest, in order to renew the available water resources. Materials like nanoparticles, polymers, and simple organic compounds, inorganic clay materials in the form of thin film, membrane or powder have been employed for water treatment. Among these materials, membrane technology plays a vital role in removal of contaminants due to its easy handling and high efficiency. Though many materials are under investigation, nanofibers driven membrane are more valuable and reliable. Synthetic methodologies applied over the modification of membrane and its applications in water treatment have been reviewed in this article.
\end{abstract}

Keywords: electrospinning; nanofibers; synthesis; surface modification; interfacial polymerization; heavy metal; antibacterial 


\section{Introduction}

Nanoparticles, nanofibers and other nanostructures bring tremendous technological advancements in the field of electronics [1], catalysis [2], bioengineering [3] and environmental applications [4]. Such nanostructures using various materials such as polymeric [5], inorganic metal/polymer composite [6] with variations in their composition, configuration and assembly have been produced by various techniques such as electrospinning [7], template assisted synthesis [8], phase separation [9], self assembly [10], solvent evaporation [11], drawing-processing method [12] and doctor blading method [13]. Among them, electrospinning is one of the most versatile and simple techniques, which has been applied to fabricate one dimensional nanostructures viz., nanofibers. Recently, numerous journal articles have documented electrospun nanofibrous "Membranes" (ENMs) for water treatment applications. A review article by Balamurugan et al. [14] reports on recent trends in nanofibrous membranes and their suitability for air and water filtration applications, preparation and characterization of electrospun nanofibers membranes and their possible applications in water treatment. Feng et al. [15] and Subramanian et al. [16] report on "New Directions of nanofibers in nanofiltration applications". These are some of very recent reports which emphasize the importance of ENMs in water technology.

ENMs have unique and interesting features, such as high surface area to volume ratio, large porosity, good mechanical properties and good water permeability, which provides a major contribution towards water treatment. These nanofibers were employed for the various water treatment applications based on their thickness, porosity, and surface roughness. The most widely applied filtration methods are microfiltration [17], ultrafiltration [18], nanofiltration [19], reverse osmosis [20] and forward osmosis and pressure retarded osmosis [21]. Among them, electrospun nanofiber membranes were exploited for the first three applications, which are covered in this review.

\section{Nanofiber Preparation-Electrospinning Technique}

Electrospinning is a versatile technique for manufacturing of nanofibers with different diameter and varied morphologies. Ultrafine nanofibers from micro to nano scale can be produced with ease. Solution viscosity, applied voltage range, humidity, tip to the collector distance are some of the important parameters that governs the formation of nanofibers. Variations in the above mentioned parameters will result in formation of thin to thick nanofibers and smooth to corrugated surfaces. A simple diagram of the electrospinning set up is shown in Figure 1.

In this process, a high voltage is applied to create an electrically charged jet of polymer solution from a syringe. The voltage is applied gradually and when the applied voltage overcomes the surface tension of the polymer solution, a Taylor cone appears and it spins down as a fiber to reach the collector plate. Before reaching the collector, the solvent evaporates and the polymer solidifies and gets collected as fibers. One end of the supply is connected to a syringe needle and the other to the collector that is grounded. Solution from the jet which is held by the surface tension will overcome once induces a charge on the surface of the liquid. Repulsion and contraction of the surface charges to the counter electrode cause a force directly opposite to the surface tension. As the voltage increased, the Taylor cone formed from the tip of needle surface elongates, i.e., the fluid elongates to attain a 
critical value where the repulsive force overcomes the surface tension and discharge. The discharged polymer solution jet undergoes an instability and elongation process, which allows the jet to become very long, uniform and thin fibers.

Although electrospinning is a methodology with numerous potential in various applications, one of the main disadvantages is the disability to achieve large scale productivity. Recently, multijet [22] and needless electrospinning techniques [23] are emerging to bridge the gap of large scale manufacturing.

Figure 1. Electrospinning set up.

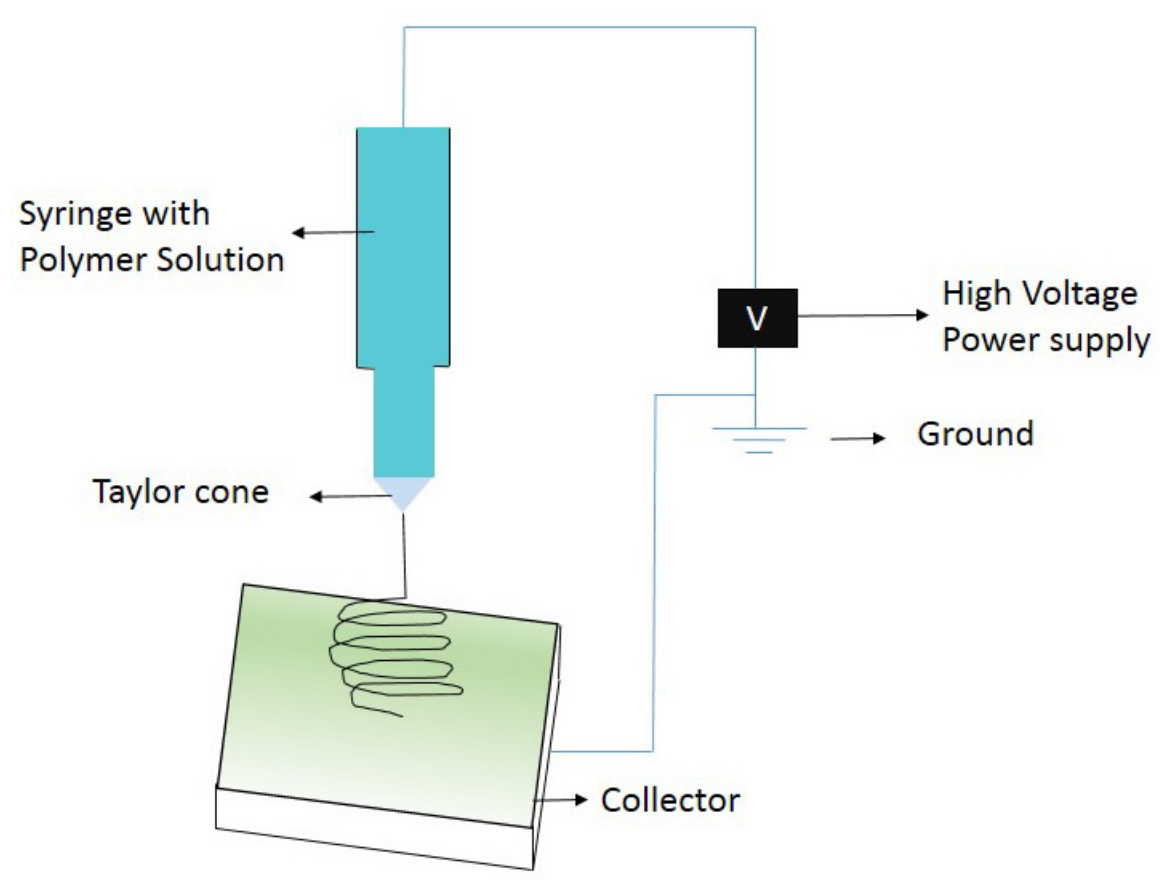

\section{Modifications of Electrospun Nanofiber Membranes (ENMs)}

\subsection{Surface Modification of ENMs}

Electrospun nanofibers are being synthesized at an increasing rate to meet its demand for various applications. Many different methods of synthesis of polymer for electrospinning to the targeted applications are available. The established methods include sol-gel synthesis [24], in situ polymerization [25], surface modification [26], plasma induced grafting [27], Graft polymerization [28], blending [29], polymer-inorganic composites formation techniques [30], etc. The resultant physical morphology and mechanical properties vary depending on the polymeric concentration and spinning condition employed during the process. Selectivity in contaminant removal, mechanical strength, and porosity of the polymer network can be modified in the ENMs in order to improve their performances towards water purification. The surface modifications of the ENMs enhance the nanofibers matrix properties such as availability of functional groups on the surface of nanofibers. Some of the other surface modification techniques are oxidation process [31], plasma treatment [32], solvent vapor treatment [33] and surface coating [34].

Cellulose, a biopolymer made nanofibers is commonly used as adsorbent for the water filtration studies. The optimal required capacity of the cellulose fiber was not attainable, due to its low surface 
area and stability. Synthetic modifications of the cellulose materials with organic functional groups are very important in order to improve the polymers activity with the pollutant either by adsorption or sensing. Stephen et al. [35] modified nanofibers with oxolone-2,5-dione, which not only enhanced the surface area of the nanofiber mat and also helped in detecting heavy metals like cadmium and lead. The adsorption capacities based on time studies of these membranes (Figure 2) were compared with commercial adsorbents such as Dowex and Amberlite resin. They also suggested that these modified nanofibers membranes can be regenerated by treating with nitric acid and reused.

Figure 2. Effect of contact time on adsorption: (A) $\mathrm{Pb}$ and (B) $\mathrm{Cd}$ (I: cellulose and II: cellulose-g-oxolane-2,5-dione nanofibers). (Reprinted with permission from [35]. Copyright 2011 Elsevier).
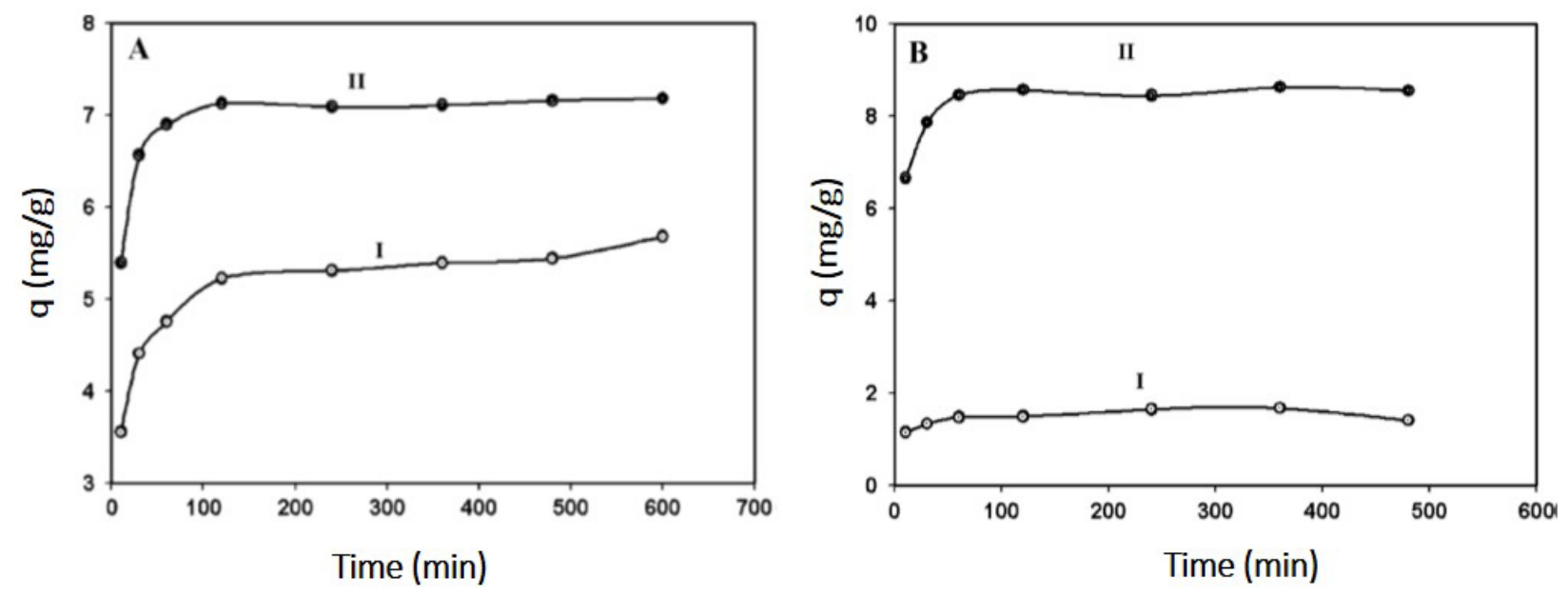

The modification of chitosan fibers was conducted by Schiffman et al. by crosslinking [36] using Glutaratldehyde and shciffs imine. Followed by Schiffman, Haider et al. [37] reported the solubility of chitosan nanofibers by treatment with trifluoroacetic acid (TFA). TFA forms a salt and exists in the form of ammonium cation and trifluoroacetate anion in the fibers. The amine group of chitosan was made available when this nanofiber was subjected to base treatment with $\mathrm{K}_{2} \mathrm{CO}_{3}$. The potassium cation binds with acetate and undergoes neutralization. This neutralization has allowed free amine group, which preferred to absorb more heavy metals. The salts helped the nanofiber mats to remain stable in aqueous medium to remove the contaminants. They reported that $\mathrm{Cu}$ (II) adsorption of nanofibers were $\sim 6$ and $\sim 11$ times higher than chitosan microsphere $(80.71 \mathrm{mg} / \mathrm{g})$ and the plain chitosan $(45.20 \mathrm{mg} / \mathrm{g})$, respectively.

Nanofiber template assisted synthesis of Silica nanofibers were studied by Li et al. [38] for the removal of heavy metals like mercury from waste water. Mixture of ethanol, $\mathrm{HCl}$, (3-mercaptopropyl) trimethoxysilane were hydrolyzed and coated onto the PAN nanofibers template. After drying, the nanofibers template was removed by dissolving the PAN in DMF to produce zonal mercaptopropyl silica (ZMS) nanofibers (Scheme 1). The maximum adsorption capacity exhibited for ZMS nanofibers within $60 \mathrm{~min}$ of contact time was $57.49 \mathrm{mg} / \mathrm{g}$ compared to pure silica nanofibers of $1.36 \mathrm{mg} / \mathrm{g}$. 
Scheme 1. Fabrication procedure of zonal mercaptopropyl silica nanofibers obtained by dissolution of the PAN nanofiber templates with DMF. (Reprinted with permission from [38]. Copyright 2011 Elsevier).

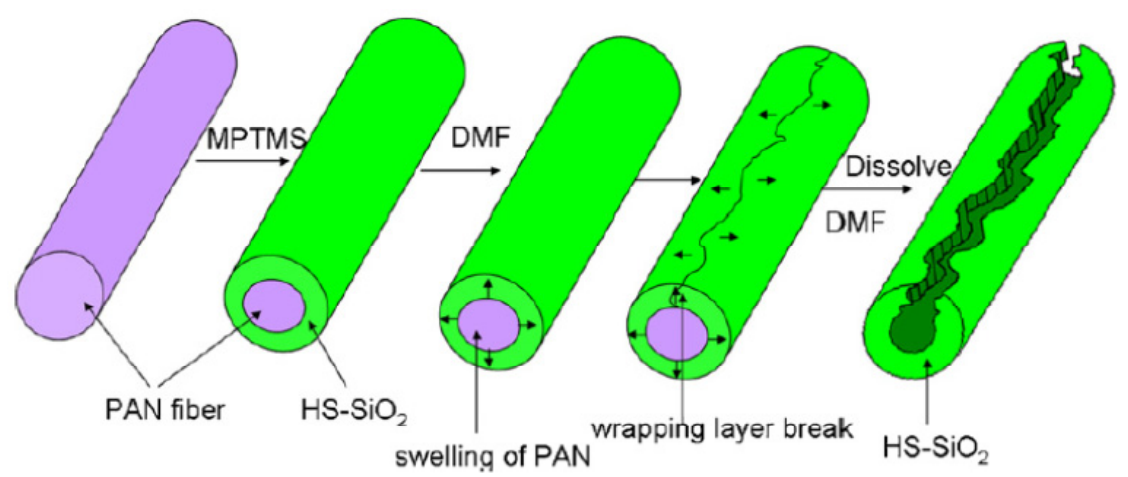

In situ polymerization of fluorinated polybenzoxazine layer (F-PBZ) incorporated with silica nanoparticle was carried out on the cellulose acetate nanofibers surface by Shang et al. [39] These modified nanofiber exhibited superhydrophobicity with the water contact angle of $161^{\circ}$ and superoleophilicity of $3^{\circ}$. This membrane showed an excellent separation of oil-water mixtures and also worked stable with wider $\mathrm{pH}$ range (2-14) suggest that they can be used for practical oil-polluted water treatments and oil spill cleanup. Ma et al. [40] reported on the fabrication of polysulfone nanofibers and its modifications with MAA (methacrylic acid) by grafting technique (Scheme 2). They treated PSU nanofibers to air plasma followed by immersing nanofibers in the solution of methacrylic acid to form PMAA grafted PSU nanofibers membrane. Toluidine blue O (TBO dye) were removed using these nanofibers and their adsorption capacity was $\sim 380 \mathrm{nmol} / \mathrm{mg}$. Protein ligands (BSA) were covalently functionalized and immobilized on the PMMA grafted PSU membranes. These ENMs showed lower pressure drop and high flux $\left(2 \mathrm{~mL} / \mathrm{cm}^{2} \mathrm{~min}\right)$ compared to the conventional membrane (5-20 psi).

Scheme 2. Schematic diagram of the surface modification process of the electrospun PSU fiber. Followed by the absorption of TBO. (Reprinted with permission from [40]. Copyright 2006 Elsevier).

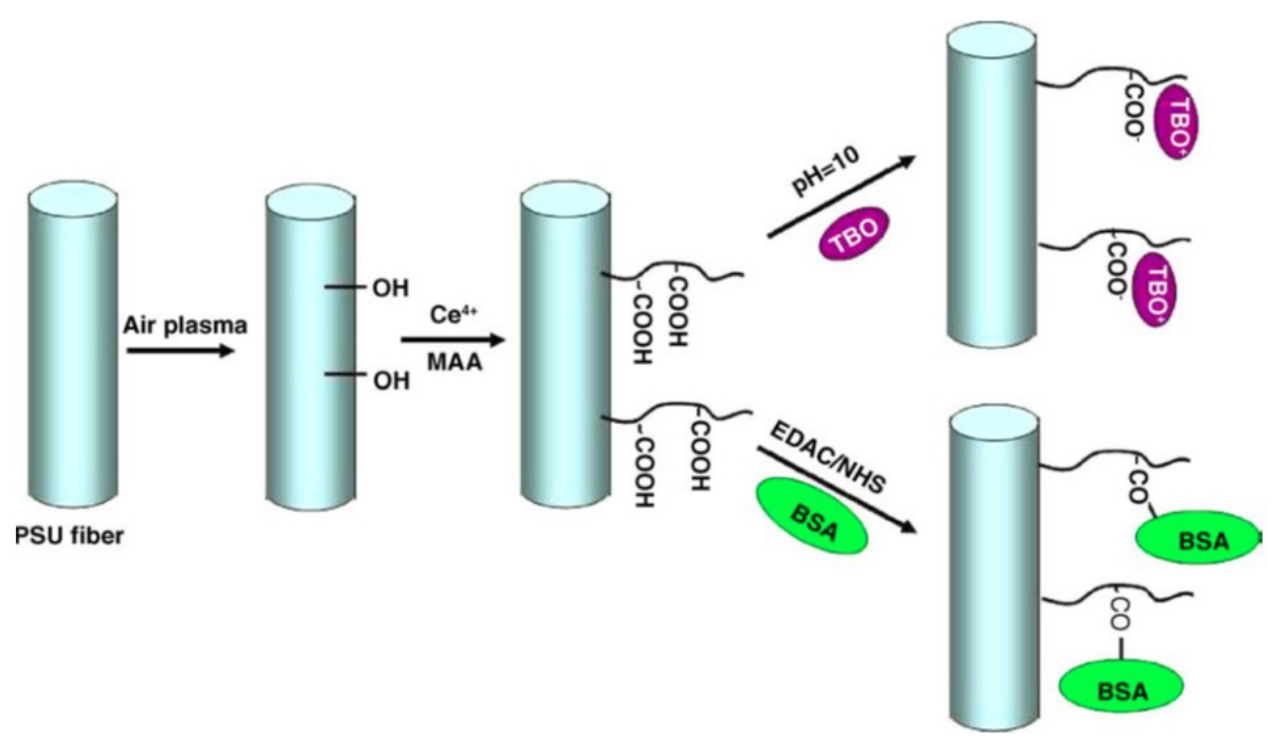


Yoon et al. [41] reported on the modification of poly (ether sulfone) (PES) nanofiber by adding mixed solvents (DMF: NMP) to improve the mechanical properties and oxidation process. The hydrophilicity of the membranes were improved by treatment of the nanofibers with $3 \% w / v$ of ammonium per sulfate, whereas improvement in mechanical strength of modulus and strength 570\% and $360 \%$ respectively were observed by the addition of high boiling solvent NMP with DMF (50\%:50\%) The hydrophilicity values for the untreated and treated membranes were found to be $120^{\circ}$ and $28^{\circ}$ respectively. Silver and silver ions have been widely used as an antimicrobial agent. The incorporation of silver ions into nanofibrous membranes by electrospinning is an attractive method to fabricate nanofibers having the ability to remove pathogen and suspended particle from waste water. Biorge et al. [42] used different polymer membranes immersed in $\mathrm{AgNO}_{3}$ followed by $\mathrm{NaBH}_{4}$ reduction, which resulted in the formation of silver ions, which acted as an antibacterial agent and inhibits/disrupts the bacterial cell. The clean water permeability (CWP) was also quite high for these membranes.

Microporous membranes were produced by Li et al. [43] to control the pore size of the electrospun membrane by annealing. Pore size reduction from 2.8 to $0.9 \mu \mathrm{m}$ with reduced porosity were observed when annealed at different temperatures $\left(90-105^{\circ} \mathrm{C}\right)$ and at different time intervals (30-120 min). The tensile strength was increased about 8 fold from 15.4 to $126 \mathrm{MPa}$ with a major change in the contact angle. These nanofiber membranes efficiently remove $\mathrm{TiO}_{2}$ particles. Furthermore, hot pressing of nanofibers with different pressure value has enhanced the membrane performance in particle rejection [44]. An applied pressure of $0.14 \mathrm{Mpa}$ has reduced the bubble point of the hot pressed membrane and further increasing the pressure has resulted in drastic decrease in the bubble point. The SEM images of the hot pressed membrane were represented in Figure 3.

Figure 3. Thickness of (a) electrospun nanofibrous membranes (ENM)-control; (b) ENM-1; (c) ENM-2 and (d) ENM-3. (Reprinted with permission from [44]. Copyright 2011 Elsevier).

(a)

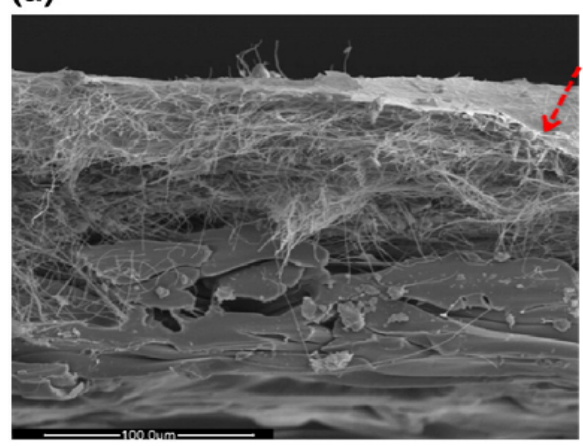

(c)

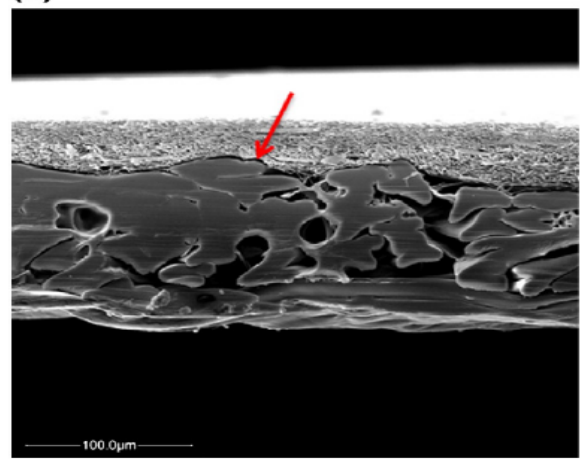

(b)

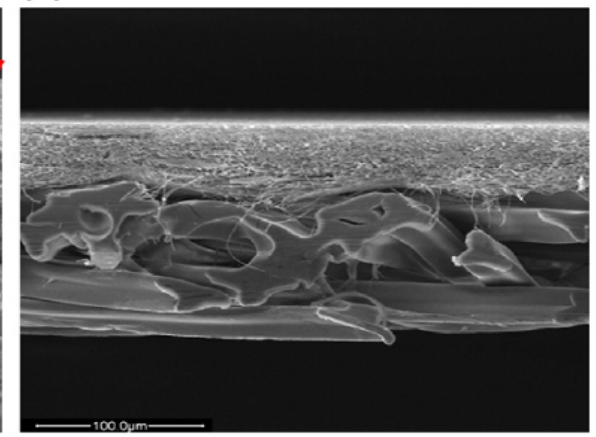

(d)

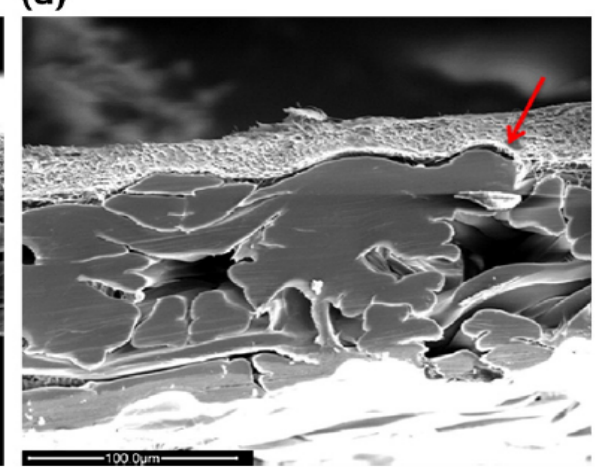


Figure 3 a represents the loose structure of electrospun nanofibrous membranes before hot pressing and it can be easily compressible after hot press (dotted arrow on top layer) as shown in Figure $3 b-d$ indicates the well-organized structure after hot pressing other nanofibers membrane (arrow indicated the top layer after hot press).

Nitrile group of polyacrylonitrile (PAN) nanofiber membranes were reduced to amino groups and coupling of hydrophilic flexible spaces followed by reaction with poly hexamethylene guanidine hydrochloride (PHGH) were carried out by Mei et al. [45] the spacer groups have improved the hydrophilicity of the membrane and guanidine hydrochloride acted as an antibacterial agent. The resulting PHGH immobilized nanofiber membranes exhibited highly effective antibacterial activities even after 3 cycles of antibacterial assays. The pure water flux of unmodified and modified electrospun nanofibers were measured using dead end filtration method which include $\mathrm{PAN}, \mathrm{PAN}-\mathrm{NH}_{2}$, PAN-NH ${ }_{2}-$ GDGE (spacer group)-PHGH (antibacterial agent), and PAN-NH ${ }_{2}-$ PEGDGE (spacer group)-PHGH (antibacterial agent) had average water flux of 15,515, 16,194, 26,276, and 30,009 L/m $\mathrm{m}^{2} \mathrm{~h}$, respectively. All these surface modifications were summarized in Table 1.

Table 1. Nanofiber-surface modification.

\begin{tabular}{|c|c|c|c|c|c|c|}
\hline S. No & Material & Modification & Active group & Target metal & Removal & Ref. \\
\hline \multirow[b]{2}{*}{1} & \multirow{2}{*}{ chitosan } & \multirow{2}{*}{ neutralization with $\mathrm{K}_{2} \mathrm{CO}_{3}$} & \multirow{2}{*}{$-\mathrm{NH}_{2}-$, amine } & $\mathrm{Cu}(\mathrm{II})$ & $485.44 \mathrm{mg} / \mathrm{g}$ & \multirow{2}{*}[37]{} \\
\hline & & & & $\mathrm{Pb}(\mathrm{II})$ & $263.15 \mathrm{mg} / \mathrm{g}$ & \\
\hline 2 & silica & zonal dissolution of PAN & $-\mathrm{SH}-$, Thiol & $\operatorname{Hg}(\mathrm{II})$ & $57.49 \mathrm{mg} / \mathrm{g}$ & [38] \\
\hline 3 & cellulose acetate & In situ polymerization & $\begin{array}{c}\text { fluorinated } \\
\text { polybenzoxazine }\end{array}$ & oil water & maximum & [39] \\
\hline 4 & poly sulfone & graft copolymerization & carboxyl group & $\begin{array}{c}\text { toluidine blue } \\
\text { O,BSA }\end{array}$ & $380 \mathrm{nmol}$ of $\mathrm{TBO} / \mathrm{mg}$ of TBO & [40] \\
\hline 5 & poly ether sulfone & $\begin{array}{l}\text { 1. solvent induced fusion } \\
\text { 2. oxidation }\end{array}$ & carbonyl & waste water & $\begin{array}{l}\text { 1. flux: } 2626 \mathrm{~L} / \mathrm{m}^{2} \mathrm{~h} \text { psi } \\
\text { 2. flux: } 2913 \mathrm{~L} / \mathrm{m}^{2} \mathrm{~h} \text { psi }\end{array}$ & {$[41]$} \\
\hline 6 & $\begin{array}{l}\text { PETE, PCTE, } \\
\text { PTFC, PA }\end{array}$ & $\mathrm{AgNO}_{3}$ reduction & $\mathrm{Ag}$ & $\begin{array}{l}\text { pathogen, } \\
\text { waste water }\end{array}$ & $\begin{array}{c}\text { turbidity removal: } 99.25 \% \\
\text { COD: } 94.73 \% \\
\mathrm{NH}^{+}: 93.98 \% \\
\end{array}$ & {$[42]$} \\
\hline 7 & poly lactic acid & annealing & $-\mathrm{COOH}-$ & $\mathrm{TiO}_{2}$ removal & $85 \%$ rejection & {$[43]$} \\
\hline 8 & polyacrylo nitrile & $\begin{array}{c}\text { hot press interfacial } \\
\text { polymerization }\end{array}$ & $-\mathrm{CN}-$ & $\begin{array}{c}\text { salt rejection } \\
\mathrm{MgSO}_{4}\end{array}$ & $86.5 \%$ & {$[44]$} \\
\hline 9 & polyacrylo nitrile & coupling & $-\mathrm{NH}_{2-}$ & antibacterial & $53.7 \%-99.9 \%$ & [45] \\
\hline
\end{tabular}

Zhao et al. [46] applied the coating of polymer solutions as a barrier layer on ENMs to enhance the performance of ultrafiltration or nanofiltration medium. Chitosan, modified chitosan with glutaraldehyde, terephthaloyl chloride were tested. The modified PVDF membranes showed good flux rate and rejection efficiency to bovine serum albumin filtration at $0.2 \mathrm{MPa}$. The flux of $70.5 \mathrm{~L} / \mathrm{m}^{2} \mathrm{~h}$, rejection efficiency of $>98 \%$ were reported for the ENMs when compared to the commercially available UF membranes.

\subsection{Interfacial Polymerization}

The main application of the interfacial polymerization on the electrospun nanofibrous materials is nanofiltration. Nanofiltration technique uses thin film composite membrane media for the removal of 
salts from the brackish water and sea water. These membranes have the basic configuration of (1) top ultrathin selective barrier layer; (2) middle porous support membrane and (3) bottom non-woven fabric to maintain strength of the whole configuration. Layers 1 and 2 can be fine tuned in order to control the performances of the membrane.

Various parameters have to be taken into consideration in the interfacial polymerization, such as reactant concentration, the partition coefficient of the reactant, the reactivity ratio, kinetics and diffusion and processing procedure [47].

Many reports have documented the modifications of the barrier layer on top of the porous polymer membrane. Yoon et al. [48] reported the interfacial polymerization at three different ratios of piperazine and bipiperidine on PAN nanofiber membranes. The study involves the rejection of divalent $\mathrm{MgSO}_{4}$ (2000 ppm) using cross flow technique. The rejection rate was improved when the concentration of Piperazine increased from $0.25 \%$ to $1 \%$ but the permeation reduced due to the thick barrier layer formation ( $>95 \%$ removal of salt), at pressure range of 70-190 psi. This was achieved by monomer solution with permeate flux 2.4 times greater than the TFC membrane.

Modification in the barrier layer enhances the water treatment properties. Changes in the additives to the barrier layer and heat treatment to the support membrane improve to the permeation flux 2 to 3 times higher. The same methodology of IP was carried out by Yung et al. [49] with PES support membranes. Ionic liquids (IL) were added as the additives to the barrier layer, which acts as a substitute to organic solvents. The ILs did not contribute to the polymerization process; rather, they worked between the surfactant and ionic salt to vary the aqueous phase during interfacial polymerization. The addition of IL tightens the crosslinking polyamide barrier layer by propagating the polymerization process and it leads to $138 \%$ improved rejection of $\mathrm{NaCl}$ when compared to non IL treated membranes $(24.3 \% \mathrm{NaCl})$.

Wu et al. [50] reported the modifications of interfacial polymerization using B-cyclodextrin (CD). Trimesoyl chloride, triethanolamine and $\mathrm{CD}$ were used as the interfacial polymerization additives. Concentration of $1.8 \%(w / v)$ of $\mathrm{CD}$ in aqueous phase shows a 2 fold increase in the value of water flux of TFNC than normal polyester membranes. This TFNC indicates remarkable increase in salt rejection and surface charge. The antifouling properties of this TFNC had been discussed in this research article. The higher hydroxyl content on $\mathrm{CD}$ inhibits the crosslinking reaction and leads to strong intermolecular hydrogen bonding which results in smoother membrane surface.

\subsection{Other Modifications}

Blending of PVDF with surface modified macromolecules were studied by Kaur et al. [51] and the macromolecules were synthesized separately using urethane prepolymer with different molecular weighted polyethylene glycols (PEGs) and these blends shows significant improvement in the hydrophilicity of the blend fibers. Poly (vinylidenefluoride) (PVDF) when blended with clay nanocomposites the hydrophobicity of the membrane increases in the mixture. The highest water contact angle achieved was $154.20^{\circ} \pm 3.04^{\circ}$ and melting point of the PVDF-clay electrospun nanofiber membrane increases with the increasing concentration of clay. These increments in the melting point indicates clay's role in the crystallization process of the nanocomposite membrane [52]. Electrospinning followed by surface modification of PVDF nanofibers membrane produces superhydrophobic 
membranes. The modification includes dopamine surface activation, silver nanoparticle deposition and hydrophobic treatment. These unmodified and modified membrane (I-PVDF) can achieve a high and stable water flux of $31.6 \mathrm{~L} / \mathrm{m}^{2} \mathrm{~h}$ using a $3.5 \mathrm{wt} \% \mathrm{NaCl}$ as the feed solution while the feed and permeate temperatures were fixed at $333 \mathrm{~K}$ and $293 \mathrm{~K}$, respectively [53].

A high flux thin film nanofibrous composite (TFNC) membrane based on PAN nanofibers coupled with thin barrier layer of cross linked poly vinyl alcohol. With a middle-layer PAN scaffold with porosity of $85 \%$ and cross-linked PVA barrier layer with thickness of about $0.5 \mu \mathrm{m}$, the TFNC membrane system were tested for ultrafiltration (UF) applications. These material exhibits a very high flux up to 12 times higher than that of conventional PAN UF membranes and excellent rejection ratio of (>99.5\%) for separation of oil/water mixture of $1500 \mathrm{ppm}$ in water over a long time period (tested up to $190 \mathrm{~h}$ ) at pressure range up to $130 \mathrm{psig}$ [54].

Poly (vinyl alcohol) (PVA)/polyacrylonitrile (PAN) nanofibrous composite membranes were prepared by electrospinning. PVA nanofiber layers were spun thicknesses of several micrometers on the electrospun PAN nanofibrous substrate. The spun PVA nanofibers were melted by water vapor to form a thin film of barrier layer and chemical crosslinking in glutaraldehyde water/acetone solution. Highest permeate flux of $210 \mathrm{~L} / \mathrm{m}^{2} \mathrm{~h}$ was achieved with the rejection of $99.5 \%$ for the membrane under the operating pressure of $0.3 \mathrm{MPa}$. This methodology opens a way to fabricate membranes with other polymeric materials and its treatment with suitable solvent vapour to form TFNC membranes [33]. The same methodology was handled by Huang et al. [55], where a post-treatment approach was demonstrated to improve the mechanical properties of polymers like polyacylonitrile (PAN) and polysulfone (PSu). The mechanical strength of this polymer membrane was improved by the solvent-induced fusion of inter-fiber junction points. The treated membranes showed significant enhancement on tensile strength and Young's Modulus while high porosity and water permeability were retained.

Polyamide made Reverse Osmosis membranes were modified by free-radical graft polymerization of 3-allyl-5,5-dimethylhydantoin (ADMH) using 2,2-azobis (isobutyramidine) dihydrochloride as an initiator. The water flux of the ADMH-grafted membranes was higher with slightly decreased salt rejections. The chlorine resistances of the ADMH-grafted membranes were significantly improved when compared to the raw membrane [56]. PVDF nanofibers membrane was modified by grafting acrylic acid and meth acrylic acid both by chemically and plasma. High water flux of $150 \mathrm{~kg} / \mathrm{h} \mathrm{m}^{2}$ at an operating pressure of $4 \mathrm{psig}$, and a 79\% removal of polyethylene oxide (molecular weight $400 \mathrm{kDa}$ ) were achieved [57].

\section{Application of ENMs in Water Treatment}

\subsection{Heavy Metal Removal}

Heavy metals generated by industries, indiscriminate human activities, etc., can cause serious damages to both environment and human health. These heavy metals are quite often mixed with water resources and are also well distributed in the entire environment. Removal of these pollutants from water resources is a major concern and many researches are focusing to address this issue. Nanofibers 
play a major role among these available purification/removal techniques. Few such pollutants and its removal by nanofibers will be discussed in this section.

Among the heavy metal ions released into the environment, chromium is considered as a primary toxic pollutant in water resources. The hexavalent chromium poses serious threats to human by causing cancer. Many technologies and materials have been employed and nanofiber membrane technology is preferable due to its remarkable characteristics like large porosity and surface area as mentioned before. Individual polymer or composites exhibits tremendous performances against chromium removal. Taha et al. [58] reported the synthesis of amine functionalized cellulose acetate/silica composite nanofiber membranes. The amine functionalized nanofibers, due to the electrostatic interaction/chelation process, enables chromium(VI) adsorption and removal and were quantized to be $19.45 \mathrm{mg} / \mathrm{g}$. Removal of Cr(II) up to $97 \mathrm{mg} / \mathrm{g}$ by changing the polymer matrix from CA to PVA have also been reported by same group [59] The smaller diffusion resistance of $\mathrm{Cr}^{3+}$ leads to easy entry and easy binding with the mesoporous membrane.

Composites membranes of $\mathrm{PAN} / \mathrm{FeCl}_{3}$ exhibit about $110 \mathrm{mg} / \mathrm{Cr} \mathrm{g}$ removal and converts $\mathrm{Cr}(\mathrm{IV})$ to $\mathrm{Cr}(\mathrm{III})$, which is less harmful. The mechanism of the nanofibers membrane process is as follows [60]:

$$
\begin{aligned}
& \mathrm{PAN}-\mathrm{Fe}(\mathrm{II}) \mathrm{OH}^{+}+\mathrm{Cr}_{3} \mathrm{O}_{7}{ }^{2-} \rightarrow \mathrm{PAN}-\mathrm{Fe}_{x}(\mathrm{III}) \mathrm{Cr}(\mathrm{III})(\mathrm{OH})_{3}+\mathrm{H}^{+} \\
& \mathrm{PAN}-\mathrm{Fe}(\mathrm{II}) \mathrm{OH}^{+}+\mathrm{Cr}_{2} \mathrm{O}_{7}^{2-} \rightarrow \mathrm{PAN}-\mathrm{Fe}(\mathrm{III})_{x} \mathrm{Cr}(\mathrm{III})_{x}(\mathrm{OH})_{2}+\mathrm{H}^{+}
\end{aligned}
$$

Increase in the $\mathrm{FeCl}_{3}$ content reduces the adsorption of chromium and the excess iron will diffuse into the solution and reacts with chromium reducing its concentration in solution. In relation to this data, Li et al. [61] reported the composite membrane made of polyamide 6 and $\mathrm{Fe}_{x} \mathrm{O}_{y}$. The adsorption capacity of $150 \mathrm{mg} / \mathrm{g}$ was reported which is higher than the previously reported values for $\mathrm{Cr}(\mathrm{VI})$ removal. The formation of Fe nanoparticles and its protonated form helps in adsorption/reduction of $\mathrm{Cr}(\mathrm{VI})$ to $\mathrm{Cr}(\mathrm{III})$.

$$
\mathrm{HCrO}^{4-}+3 \mathrm{Fe}^{2+}+7 \mathrm{H}^{+} \rightarrow \mathrm{Cr}^{3+}+3 \mathrm{Fe}^{3+}+4 \mathrm{H}_{2} \mathrm{O}
$$

$\mathrm{Xu}$ et al. [62] reported the hierarchical growth of nanofiber membranes using thermo plastic elastomeric ester (TPEE) and Iron oxide. Copper and lead were removed by chitosan nanofibers mats [24]. The removal of these metal ions was either by chelation/electrostatic adsorption method and the adsorption capacity is reported to be $485.44 \mathrm{mg} / \mathrm{Cu} \mathrm{g}$ and $263.15 \mathrm{mg} / \mathrm{Pb}$ g, which is six times greater than the previously reported values.

Removal of other toxic metal ions like nickel, cadmium along with copper and lead have been reported by Aliabadi et al. [63] Composition of PEO and chitosan nanofiber membranes was employed to study the purification process. The mesoporous composite nanofibers exhibit $183.4 \mathrm{mg} / \mathrm{Ni} \mathrm{g}$, $172.3 \mathrm{mg} / \mathrm{Cu} \mathrm{g}, 150.3 \mathrm{mg} / \mathrm{Cd} \mathrm{g}, 143.4 \mathrm{mg} / \mathrm{Pb} \mathrm{g}$ for a pseudo first order model and $249.9 \mathrm{mg} / \mathrm{Ni} \mathrm{g}$, $229.2 \mathrm{mg} / \mathrm{Cu} \mathrm{g}, 196.6 \mathrm{mg} / \mathrm{Cd} \mathrm{g}$ and $195.1 \mathrm{mg} / \mathrm{Pb} \mathrm{g}$ for second order removal from the solution.

\subsection{Microbial Removal}

An atmospheric helium plasma treatment was employed to reduce $\mathrm{AgNO}_{3}$ to $\mathrm{Ag}$ nanoparticles. This prepolymer solution with PAN electrospun to form nanofibers membranes with Ag nanoparticles sized in the range of 3 to $6 \mathrm{~nm}$. Gram positive Basillus cereus and gram negative Escherichia coli microorganisms were tested using this fiber. The fibers without silver compounds ended with no 
antibacterial activity compared to the Ag nanoparticle doped PAN nanofibers [64]. The same methodology was applied to PAN nanofibers by amidoxime functionalized PAN. Coordination of $\mathrm{Ag}^{+}$ and its reduction to $\mathrm{Ag}$ nanoparticles were tested for microbes like S.aurieus and E. coli. The ASFPAN-3, which were amidoxime functionalized nanofibers after immersion for 20 min in $\mathrm{NH}_{4} \mathrm{OH}$ showed $\log 7$ reductions (complete kill). The amidoxime group tends to bind with metal ions like $\mathrm{Mg}^{2+}$ and $\mathrm{Ca}^{2+}$, which are essential for the bacterial stability and replication through co-ordination. The competency of the amidoxime coordination with bacterial holding increased and more metals bind to amidoxime group rather on to the cell membrane of the bacterial cell. This process restricts the cellular replication and growth of the bacteria and kills the cell. The same trend was observed for both $\mathrm{AgNO}_{3}$ solution dipped nanofibers membrane for $30 \mathrm{~min}$ and Ag nanoparticle/PAN nanofibers, exhibits $\log 7$ reduction bacteria [65]. Few other reports using nanofiber mats were tabulated in Table 2.

Table 2. Nanofibers for removal of bacteria.

\begin{tabular}{|c|c|c|c|c|c|c|c|}
\hline Polymer & $\begin{array}{c}\text { Membrane } \\
\text { diameter }(\mathbf{n m})\end{array}$ & \multicolumn{4}{|c|}{ Properties } & $\begin{array}{c}\text { Antibacterial } \\
\text { activity }\end{array}$ & Ref. \\
\hline Poly acrylonitrile (PAN) & 100 & \multicolumn{2}{|c|}{ Mean Pore Size: $0.22 \pm 0.01 \mu \mathrm{m}$} & \multicolumn{2}{|c|}{ Flux: $1.5 \mathrm{~L} / \mathrm{m}^{2} \mathrm{~h}$} & E. coli & [66] \\
\hline Polyacrylonitrile (PAN) & 50 & \multicolumn{2}{|c|}{ Mean Pore Size: $0.4 \mu \mathrm{m}$} & \multicolumn{2}{|c|}{-} & $\begin{array}{l}\text { S. aureus } \\
\text { E. coli }\end{array}$ & [67] \\
\hline \multirow{7}{*}{ Nylon-6 } & \multirow{7}{*}{650} & \multicolumn{4}{|c|}{ OD culture at $600 \mathrm{~nm}$} & \multirow{7}{*}{$\begin{array}{l}\text { S. aureus } \\
\text { E. coli }\end{array}$} & \multirow{7}{*}{$\begin{array}{r}{[68,} \\
69]\end{array}$} \\
\hline & & \multirow{3}{*}{\multicolumn{2}{|c|}{ E. coli }} & \multicolumn{2}{|c|}{ Pristine-3.4 } & & \\
\hline & & & & \multicolumn{2}{|c|}{ Mat 1-1.57 } & & \\
\hline & & & & Ma & $2-1.75$ & & \\
\hline & & \multirow{3}{*}{\multicolumn{2}{|c|}{ S. aureus }} & \multicolumn{2}{|c|}{ Pristine-2.55 } & & \\
\hline & & & & \multicolumn{2}{|c|}{ Mat 1-1.68 } & & \\
\hline & & & & \multicolumn{2}{|c|}{ Mat 2-1.88 } & & \\
\hline \multirow{5}{*}{ Polyacrylonitrile (PAN) } & \multirow{5}{*}{200} & \multicolumn{4}{|c|}{ Zone inhibition (mm) } & \multirow{5}{*}{$\begin{array}{c}\text { B. subtilis } \\
\text { S. aureus } \\
\quad \text { E. coli }\end{array}$} & \multirow{5}{*}{ [70] } \\
\hline & & Microorganism & $\begin{array}{l}\mathrm{NaBH}_{4} \\
\text { reduction }\end{array}$ & $\begin{array}{l}\text { Heated } \\
\left(160{ }^{\circ} \mathrm{C}\right.\end{array}$ & $\begin{array}{l}\text { Heated } \\
@ 80^{\circ} \mathrm{C}\end{array}$ & & \\
\hline & & B. subtilis & 7.5 & 6 & 10 & & \\
\hline & & S. aureus & 9 & 10 & 10 & & \\
\hline & & E. coli & - & 6 & 9 & & \\
\hline
\end{tabular}

\subsection{Desalination}

Desalination an effective technology for overcoming the higher demand for water. Various desalination technologies have been developed, which include reverse osmosis (RO), membrane distillation (MD), freeze desalination (FD), electrodialysis (ED), ion exchange (IX), and nanofiltration (NF). Among them, NF technology has been emerging as one of the effective ones to desalt low salt content water due to enhanced flux, lower operational pressure and energy savings. Nanofibers are currently explored as potential membranes for desalination due to their improved flux performance. A comprehensive listing of ENMs used in desalination applications and their performances are presented in Table 3. 
Table 3. Electrospun nanofibers in the desalination application.

\begin{tabular}{|c|c|c|c|c|c|c|}
\hline $\begin{array}{c}\text { Middle layer } \\
\text { (electrospun nanofiber) }\end{array}$ & $\begin{array}{l}\text { Third } \\
\text { layer }\end{array}$ & Solute & Method & Flux $\left(L / \mathbf{m}^{2} / \mathbf{h}\right)$ & Rejection (\%) & Ref. \\
\hline $\begin{array}{l}\text { PVA/MWNT or Pebax/MWNT } \\
\text { over PET substrate }\end{array}$ & none & oil/water & $\begin{array}{l}\text { TFNC by } \\
\text { coating }\end{array}$ & 330 or 160 & n.a. & [71] \\
\hline PVA or Pebax over PET substrate & none & oil/water & $\begin{array}{l}\text { TFNC by } \\
\text { coating }\end{array}$ & 130 or 58 & PVA coated $>99.5$ & [72] \\
\hline $\begin{array}{l}10 \text { and } 4 \mathrm{wt} \% \text { of PAN over PET } \\
\text { substrate, rotating collector }\end{array}$ & none & oil/water & $\begin{array}{l}\text { TFNC by } \\
\text { coating }\end{array}$ & $\begin{array}{l}\text { TFNC an order of } \\
\text { magnitude }>\text { com. }\end{array}$ & $\begin{array}{l}99.5 \% \text {, better than } \\
\text { com. NF }\end{array}$ & [73] \\
\hline PAN & polyamides & $\mathrm{MgSO}_{4}$ & $\begin{array}{l}\text { TFNC by } \\
\text { Interfacial }\end{array}$ & $\begin{array}{c}\text { TFNC } 38 \%>\text { com. } \\
\text { NF } 270\end{array}$ & $\begin{array}{l}\text { TFNC and com. } \\
\text { are comparable }\end{array}$ & [49] \\
\hline \multirow{2}{*}{ PVDF } & \multirow{2}{*}{ polyamides } & $\mathrm{MgSO}_{4}$ & TFNC by & 0.66 & 75.7 & \multirow{2}{*}[74]{} \\
\hline & & $\mathrm{NaCl}$ & Interfacial & 0.66 & 70.2 & \\
\hline \multirow{3}{*}{ PAN } & \multirow{3}{*}{ polyamides } & \multirow{3}{*}{$\mathrm{MgSO}_{4}$} & Interfacial & & & \multirow{3}{*}[45]{} \\
\hline & & & TFNC1 & - & 88 & \\
\hline & & & TFNC2 & 81 & 84.2 & \\
\hline first layer 8 or $10 \mathrm{wt} \% \mathrm{PAN}$ & \multirow{2}{*}{ polyamides } & $\mathrm{MgSO}_{4}$ & \multirow{2}{*}{ Interfacial } & 220 & 89 & \multirow{2}{*}[75]{} \\
\hline second layer 4 or 6 or 8 wt $\%$ PAN & & $\mathrm{NaCl}$ & & 200 & 89 & \\
\hline PVDF & n.a. & 6 wt $\% \mathrm{NaCl}$ & AGMD & $11-12 \mathrm{~kg} /\left(\mathrm{m}^{2} \mathrm{~h}\right)$ & n.a. & [76] \\
\hline PVDF & \multirow{2}{*}{ n.a. } & \multirow{2}{*}{$\mathrm{NaCl}$} & \multirow{2}{*}{ DCMD } & \multirow{2}{*}{ n.a. } & 98.27 & \multirow{2}{*}[52]{} \\
\hline PVDF-clay nanocomposites & & & & & 99.95 & \\
\hline $\mathrm{PET} / \mathrm{PS}$ & polyamide & $\mathrm{NaCl}$ & Interfacial & $1.13 \mathrm{~L} \mathrm{~m}^{-2} \mathrm{~h}^{-1}$ bar $^{-1}$ & - & [21] \\
\hline
\end{tabular}

Notes: n.a.: not available; com.: Commercial membranes; AGMD: air gap membrane distillation; DCMD: direct contact membrane distillation.

The conventional middle layer was replaced with ENMs and then coating with various materials was carried out to form thin film nanocomposite (TFNC) membranes by Chu group [71-73]. They observed that the flux rate and oil rejection (oil in water emulsion) of the TFNC membranes was higher than commercial NF 270 membranes [72]. The thin layer formation through the interfacial polymerization technique by the reaction of polyamines in water with polyacid chlorides in organic solvents was also carried out by $\mathrm{Chu}$ and Ramakrishna group. The ENMs were also used as self-supporting membranes for the desalination application by Kaur et al. [77] The ENMs were also explored for membrane distillation application by Ramakrishna group [75]. The ENMs were stable up to 25 days tested and these ENMs may compete with conventional distillation and RO processes. Blending of clay nanoparticles with PVDF followed by electrospinning was carried out for direct contact membrane distillation (DCMD) process and greater than $99.95 \%$ salt rejection was achieved by Prince et al. [52].

The PAN based carbon nanofibers (CNFs) were also explored for the capacitive deionization by Wang et al. [76]. They have observed higher electrosorption capacity (4.64 mg/g) for CNFs than other materials (activated carbon (3.68), woven carbon fibers (1.87), carbon aerogel (3.33), CNTs-CNFs (3.32), mesoporous carbon (0.69), and graphene of $1.85 \mathrm{mg} / \mathrm{g}$ ), which shows that ENMs can be potentially applied in electrochemical capacitive deionization of seawater desalination. 


\subsection{Other Application}

Novel crosslinking chemistry can also be introduced into the nanofiber to improve the filtration efficiency effectively since the fiber diameter of nanofibers can be fine tuned to get smaller pore diameter than meltblown and spunbound layers for better performance of the later. This idea has been applied in the crosslinking of PVA nanofibers by maleic acid using vitriolic acid as a catalyst to improve the antiwater properties by Qin et al. [78] The filtration efficiencies of the melt blown and spunbound sublayers were, $30 \%$ and $6 \%$, respectively, whereas the filtration efficiency of complex is much higher than those sublayers after $0.5 \mathrm{~g} / \mathrm{m}^{2}$ crosslinked nanofibers membrane was electrospun on the sublayers. When $1.9 \mathrm{~g} / \mathrm{m}^{2}$ and $2.9 \mathrm{~g} / \mathrm{m}^{2}$ nanofibers webs were electrospun on the meltblown sublayers, and spunbonded sublayers, the filtration efficiencies of about $100 \%$, and $95 \%$ were observed for meltblown complex, and spunbonded complex, respectively.

The applicability of polyethersulphone ENMs supported on a PET sub-layer for liquid filtration was studied by Homaeigohar et al. [79]. The ENMs showed high permeability for the pure water flux and at high feed pressures the water permeation slowly decreased. They applied heat treatment approach to overcome the stability of these fibers and particles of size $>1 \mu \mathrm{m}$ were removed in an hour with very high flux and low pressure. When they tested for a feed containing nanoparticles $(<1 \mu \mathrm{m}$ size $)$, the major rejection was achieved within the first hour due to pore blocking.

A novel double layer PAN nanofiber membrane was reinforced with 2,2,6,6-tetramethylpiperidine1-oxyl (TEMPO) by Cao et al. [80] in which radical oxidizes jute cellulose nanowhiskers. These PAN/cellulose composite nanofibers showed good mechanical strength and high filtration efficiency for 7-10 nm particles. These nanofibers can be extended for application in the domestic drinking water and industrial waste water treatment.

\section{Future Directions and Conclusions}

Various synthetic methodologies such as in situ polymerization, addition of molecular dopants, inter or intermolecular bondings in combination with electrospinning techniques may be pursued in future to produce nanofibers with different morphologies and their filtration performances. The surface modification by grafting, interfacial polymerization, and nanoparticles coating, treatment with acids are found to be suitable methods to alter the surface properties, improve the filtration performance and antifouling properties of nanofiber membranes. In the case of heavy metal ion removal, the adsorption capacities of such modified membranes were comparable/better than conventional membranes/commercial agents. The electrospun nanofibers were also effectively used in the filtration of oil/water emulsions and microparticles.

The electrospun nanofibers can also be potentially applied in the areas of nanofiltration, membrane distillation, geothermal water desalination and capacitive deionization applications. The hot pressing step is necessary to improve the integrity of the nanofiber membranes as well as nanofiber/backing layer in the case of TFNC membranes in NF application. When the middle layer of conventional membranes was replaced with nanofibrous membranes, improved flux than conventional membranes was observed. 


\section{Conflicts of Interest}

The authors declare no conflict of interest.

\section{References}

1. Yu, H.; Guo, J.; Zhu, S.; Li, Y.; Zhang, Q.; Zhu, M. Preparation of continuous alumina nanofibers via electrospinning of PAN/DMF solution. Mater. Lett. 2012, 74, 247-249.

2. Chen, L.; Bromberg, L.; Hatton, T.A.; Rutledge, G.C. Catalytic hydrolysis of $p$-nitrophenyl acetate by electrospun polyacrylamidoxime nanofibers. Polymer 2007, 48, 4675-4682.

3. Kijenska, E.; Prabhakaran, M.P.; Swieszkowski, W.; Kurzydlowski, K.J.; Ramakrishna, S. Electrospun bio-composite (PLLA-CL)/collagen I/collagen III scaffolds for nerve tissue engineering. J. Bio. Mater. Res. B Appl. Biomater. 2012, 100B, 1093-1102.

4. Katepalli, H.; Bikshapathi, M.; Sharma, C.S.; Verma, N.; Sharma, A. Synthesis of hierarchical fabrics by electrospinning of PAN nanofibers on activated carbon microfibers for environmental remediation applications. Chem. Eng. 2011, 171, 1194-1200.

5. Barakat, N.A.M.; Abadir, M.F.; Sheikh, F.A.; Kanjwal, M.A.; Park, S.J.; Kim, H.Y. Polymeric nanofibers containing solid nanoparticles prepared by electrospinning and their applications. Chem. Eng. 2010, 156, 487-495.

6. Lim, S.K.; Lee, S.-K.; Hwang, S.-H.; Kim, H. Photocatalytic deposition of silver nanoparticles onto organic/inorganic composite nanofibers. Macromol. Mater. Eng. 2006, 291, 1265-1270.

7. Doshi, J.; Reneker, D.H. Electrospinning process and applications of electrospun fibers. J. Electrost. 1995, 35, 151-160.

8. Gopi, D.; Bhuvaneshwari, N.; Indira, J. A novel green template assisted synthesis of hydroxyapatite nanorods and their spectral characterization. Spectrochim. Acta A Mol. Biomol. Spectrosc. 2013, 107, 196-202.

9. Peng, Y.; Dong, Y.; Fan, H.; Chen, P.; Li, Z.; Jiang, Q. Preparation of polysulfone membranes via vapor-induced phase separation and simulation of direct-contact membrane distillation by measuring hydrophobic layer thickness. Desalination 2013, 316, 53-66.

10. Ding, J.; Zhang, M.; Jiang, Z.; Li, Y.; Ma, J.; Zhao, J. Enhancing the permselectivity of pervaporation membrane by constructing the active layer through alternative self-assembly and spin-coating. J. Membr. Sci. 2012, 390, 218-225.

11. Dong, Y.; Wang, M.; Chen, L.; Li, M. Preparation, characterization of P(VDF-HFP)/[bmim]BF4 ionic liquids hybrid membranes and their pervaporation performance for ethyl acetate recovery from water. Desalination 2012, 295, 53-60.

12. Lee, C.; Cao, J. Shell element formulation of multi-step inverse analysis for axisymmetric deep drawing process. Int. J. Numer. Methods Eng. 2001, 50, 681-706.

13. Liewhiran, C.; Phanichphant, S. Doctor-bladed thick films of flame-made $\mathrm{Pd} / \mathrm{ZnO}$ nanoparticles for ethanol sensing. Curr. Appl. Phys. 2008, 8, 336-339.

14. Balamurugan, R.; Sundarrajan, S.; Ramakrishna, S. Recent trends in nanofibrous membranes and their suitability for air and water filtrations. Membranes 2011, 1, 232-248. 
15. Feng, C.; Khulbe, K.C.; Matsuura, T.; Tabe, S.; Ismail, A.F. Preparation and characterization of electro-spun nanofiber membranes and their possible applications in water treatment. Sep. Purif. Technol. 2013, 102, 118-135.

16. Subramanian, S.; Seeram, R. New directions in nanofiltration applications-Are nanofibers the right materials as membranes in desalination? Desalination 2013, 308, 198-208.

17. Bazargan, A.M.; Keyanpour-Rad, M.; Hesari, F.A.; Esmaeilpour, M.G. A study on the microfiltration behavior of self-supporting electrospun nanofibrous membrane in water using an optical particle counter. Desalination 2011, 265, 148-152.

18. Shukla, R.; Cheryan, M. Performance of ultrafiltration membranes in ethanol-water solutions: Effect of membrane conditioning. J. Membr. Sci. 2002, 198, 75-85.

19. Sundarrajan, S.; Balamurugan, R.; Kaur, S.; Ramakrishna, S. Potential of engineered electrospun nanofiber membranes for nanofiltration applications. Dry. Technol. 2013, 31, 163-169.

20. Fujioka, T.; Khan, S.J.; McDonald, J.A.; Roux, A.; Poussade, Y.; Drewes, J.E.; Nghiem, L.D. $\mathrm{N}$-nitrosamine rejection by nanofiltration and reverse osmosis membranes: The importance of membrane characteristics. Desalination 2013, 316, 67-75.

21. Hoover, L.A.; Schiffman, J.D.; Elimelech, M. Nanofibers in thin-film composite membrane support layers: Enabling expanded application of forward and pressure retarded osmosis. Desalination 2013, 308, 73-81.

22. Srivastava, Y.; Marquez, M.; Thorsen, T. Multijet electrospinning of conducting nanofibers from microfluidic manifolds. J. Appl. Polym. Sci. 2007, 106, 3171-3178.

23. Niu, H.; Wang, X.; Lin, T. Upward needleless electrospinning of nanofibers. J. Eng. Fibers Fabr. 2012, 7, 17-22.

24. Teng, M.; Wang, H.; Li, F.; Zhang, B. Thioether-functionalized mesoporous fiber membranes: Sol-gel combined electrospun fabrication and their applications for $\mathrm{Hg}^{2+}$ removal. J. Colloid Interface Sci. 2011, 355, 23-28.

25. Li, L.; Wang, B.; Tan, H.; Chen, T.; Xu, J. A novel nanofiltration membrane prepared with PAMAM and TMC by in situ interfacial polymerization on PEK-C ultrafiltration membrane. J. Membr. Sci. 2006, 269, 84-93.

26. You, H.; Li, X.; Yang, Y.; Wang, B.; Li, Z.; Wang, X.; Zhu, M.; Hsiao, B.S. High flux low pressure thin film nanocomposite ultrafiltration membranes based on nanofibrous substrates. Sep. Purif. Technol. 2013, 108,143-151.

27. Aerts, S.; Vanhulsel, A.; Buekenhoudt, A.; Weyten, H.; Kuypers, S.; Chen, H.; Bryjak, M.; Gevers, L.E.M.; Vankelecom, I.F.J.; Jacobs, P.A. Plasma-treated PDMS-membranes in solvent resistant nanofiltration: Characterization and study of transport mechanism. J. Membr. Sci. 2006 275, 212-219.

28. Deng, B.; Yang, X.; Xie, L.; Li, J.; Hou, Z.; Yao, S.; Liang, G.; Sheng, K.; Huang, Q. Microfiltration membranes with $\mathrm{pH}$ dependent property prepared from poly(methacrylic acid) grafted polyethersulfone powder. J. Membr. Sci. 2009, 330, 363-368.

29. Zhang, P.Y.; Xu, Z.L.; Yang, H.; Wei, Y.M.; Wu, W.Z.; Chen, D.G. Preparation and characterization of PVDF-P(PEGMA-r-MMA) ultrafiltration blend membranes via simplified blend method. Desalination 2013, 319, 47-59. 
30. Kango, S.; Kalia, S.; Celli, A.; Njuguna, J.; Habibi, Y.; Kuma, R. Surface modification of inorganic nanoparticles for development of organic-inorganic nanocomposites-A review. Prog. Polym. Sci. 2013, 38, 1232-1261.

31. Setyadhi, L.; Liu, J.C. Oxidation-microfiltration removal of Fe(II) from water. Desalination Water Treat. 2013, 51, 374-383.

32. Saxena, N.; Prabhavathy, C.; De, S.; Dasgupta, S. Flux enhancement by argon on Technology (II) from wet polyethersulfone membranes. Sep. Purif. Technol. 2009, 70, 160-165.

33. Wang, X.; Zhang, K.; Yang, Y.; Wang, L.; Zhou, Z.; Zhu, M.; Hsiao, B.; Chu, B. Membrane development of hydrophilic barrier layer on nanofibrous substrate as composite membrane via a facile route. J. Membr. Sci. 2010, 356, 110-116.

34. Wei, J.; Wang, X.; Zhang, K.; Zhou, K. Preparation and characterization of high flux ultrafiltration composite membrane based on nanofibrous substrate and cellulose acetate coating. In Proceedings of 2009 International Conference on Advanced Fibers and Polymer Materials, 21-24 October 2009, Shanghai, China.

35. Stephen, M.; Catherine, N.; Brenda, M.; Andrew, K.; Leslie, P.; Corrine, G. Oxolane-2,5-dione modified electrospun cellulose nanofibers for heavy metals adsorption. J. Hazard. Mater. 2011, 192, 922-927.

36. Schiffman, J.D.; Schauer, C.L. Cross-linking chitosan nanofibers. Biomacromolecules 2007, 8, 594-601.

37. Haider, S.; Park, S.Y. Preparation of the electrospun chitosan nanofibers and their applications to the adsorption of $\mathrm{Cu}(\mathrm{II})$ and $\mathrm{Pb}(\mathrm{II})$ ions from an aqueous solution. J. Membr. Sci. 2009, 328, 90-96.

38. Li, S.; Yue, X.; Jing, Y.; Bai, S.; Dai, Z. Fabrication of zonal thiol-functionalized silica nanofibers for removal of heavy metal ions from wastewater. Colloid Surfaces A Physicochem. Eng. Asp. 2011, 380, 229-233.

39. Shang, Y.; Si, Y.; Raza, A.; Yang, L.; Mao, X.; Ding, B.; Yu, J. An in situ polymerization approach for the synthesis of superhydrophobic and superoleophilic nanofibrous membranes for oil-water separation. Nanoscale 2012, 4, 7847-7854.

40. Ma, Z.; Kotak, M.; Ramakrishna, S. Surface modified nonwoven polysulphone (PSU) fiber mesh by electrospinning: A novel affinity membrane. J. Membr. Sci. 2006, 272, 179-187.

41. Yoon, K.; Hsiao, B.S.; Chu, B. Formation of functional polyethersulfone electrospun membrane for water purification by mixed solvent and oxidation processes. Polymer 2009, 50, 2893-2899.

42. Bjorge, D.; Daels, N.; de Vrieze, S.; Dejans, P.; van Camp, T.; Audenaert, W.; Hogie, J.; Westbroek, P.; de Clerck, K.; van Hulle, S.W.H. Performance assessment of electrospun nanofibers for filter applications. Desalination 2009, 249, 942-948.

43. Li, L.; Hashaikeh, R.; Arafat, H.A. Development of eco-efficient micro-porous membranes via electrospinning and annealing of poly (lactic acid). J. Membr. Sci. 2013, 436, 57-67.

44. Kaur, S.; Barhate, R.; Sundarrajan, S.; Matsuura, T.; Ramakrishna, S. Hot pressing of electrospun membrane composite and its influence on separation performance on thin film composite nanofiltration membrane. Desalination 2011, 279, 201-209. 
45. Mei, Y.; Yao, C.; Fan, K.; Li, X. Surface modification of polyacrylonitrile nanofibrous membranes with superior antibacterial and easy-cleaning properties through hydrophilic flexible spacers. J. Membr. Sci. 2012, 417-418, 20-27.

46. Zhao, Z.; Zheng, J.; Wang, M.; Zhang, H.; Han, C.C. High performance ultrafiltration membrane based on modified chitosan coating and electrospun nanofibrous PVDF scaffolds. J. Membr. Sci. 2012, 394-395, 209-217.

47. Petersen, R.J. Composite reverse osmosis and nanofiltration membranes. J. Membr. Sci. 1993, 83, $81-150$.

48. Yoon, K.; Hsiao, B.S.; Chu, B. High flux nanofiltration membranes based on interfacially polymerized polyamide barrier layer on polyacrylonitrile nanofibrous scaffolds. J. Membr. Sci. 2009, 326, 484-492.

49. Yung, L.; Ma, H.; Wang, X.; Yoon, K.; Wang, R.; Hsiao, B.S.; Chu, B. Fabrication of thin-film nanofibrous composite membranes by interfacial polymerization using ionic liquids as additives. J. Membr. Sci. 2010, 365, 52-58.

50. Wu, H.; Tang, B.; Wu, P. Preparation and characterization of anti-fouling $b$-cyclodextrin/ polyester thin film nanofiltration composite membrane. J. Membr. Sci. 2013, 428, 301-308.

51. Kaur, S.; Rana, D.; Matsuura, T.; Sundarrajan, S.; Ramakrishna, S. Preparation and characterization of surface modified electrospun membranes for higher filtration flux. J. Membr. Sci. 2012, 390-391, 235-242.

52. Prince, J.A.; Singh, G.; Rana, D.; Matsuura, T.; Anbharasi, V.; Shanmugasundaram, T.S. Preparation and characterization of highly hydrophobic poly(vinylidene fluoride) - Clay nanocomposite nanofiber membranes (PVDF-clay NNMs) for desalination using direct contact membrane distillation. J. Membr. Sci. 2012, 397-398, 80-86.

53. Liao, Y.; Wang, R.; Fane, A.G. Engineering superhydrophobic surface on poly(vinylidene fluoride) nanofiber membranes for direct contact membrane distillation. J. Membr. Sci. 2013, 440, $77-87$.

54. Yoon, K.; Hsiao, B.S.; Chu, B. High flux ultrafiltration nanofibrous membranes based on polyacrylonitrile electrospun scaffolds and crosslinked polyvinyl alcohol coating. J. Membr. Sci. 2009, 338, 145-152.

55. Huang, L.; Manickam, S.S.; McCutcheon, J.R. Increasing strength of electrospun nanofiber membranes for water filtration using solvent vapor. J. Membr. Sci. 2013, 436, 213-220.

56. Wei, X.; Wang, Z.; Zhang, Z.; Wang, J.; Wang, S. Surface modification of commercial aromatic polyamide reverse osmosis membranes by graft polymerization of 3-allyl-5,5-dimethylhydantoin. J. Membr. Sci. 2010, 351, 222-233.

57. Savoji, H.; Rana, D.; Matsuura, T.; Tabe, S.; Feng, C. Development of plasma and/or chemically induced graft co-polymerized electrospun poly(vinylidene fluoride) membranes for solute separation. Sep. Purif. Technol. 2013, 108, 196-204.

58. Taha, A.A.; Wu, Y.N.; Wang, H.; Li, F. Preparation and application of functionalized cellulose acetate/silica composite nanofibrous membrane via electrospinning for $\mathrm{Cr}(\mathrm{VI})$ ion removal from aqueous solution. J. Environ. Manag. 2012, 112, 10-16. 
59. Taha, A.A.; Qiao, J.; Li, F.; Zhang, B. Preparation and application of amino functionalized mesoporous nanofiber membrane via electrospinning for adsorption of $\mathrm{Cr}^{3+}$ from aqueous solution. J. Environ. Sci. 2012, 24, 610-616.

60. Lin, Y.; Cai, W.; Tian, X.; Liu, X.; Wang, G.; Liang, C. Polyacrylonitrile/ferrous chloride composite porous nanofibers and their strong Cr-removal performance. J. Mater. Chem. 2011, 21, 991-997.

61. Li, C.J.; Li, Y.J.; Wang, J.N.; Cheng, J. PA6@ $\mathrm{Fe}_{x} \mathrm{O}_{y}$ nanofibrous membrane preparation and its strong Cr (VI)-removal performance. Chem. Eng. J. 2013, 220, 294-301.

62. Xu, G.R.; Wang, J.N.; Li, C.J. Preparation of hierarchically nanofibrous membrane and its high adaptability in hexavalent chromium removal from water. Chem. Eng. J. 2012, 198-199, 310-317.

63. Aliabadi, M.; Irani, M.; Ismaeili, J.; Piri, H.; Parnian, M.J. Electrospun nanofiber membrane of $\mathrm{PEO} / \mathrm{Chitosan}$ for the adsorption of nickel, cadmium, lead and copper ions from aqueous solution. Chem. Eng. J. 2013, 220, 237-243.

64. Shi, Q.; Vitchuli, N.; Nowak, J.; Caldwell, J.M.; Breidt, F.; Bourham, M.; Zhang, X.; McCord, M. Durable antibacterial Ag/polyacrylonitrile (Ag/PAN) hybrid nanofibers prepared by atmospheric plasma treatment and electrospinning. Eur. Polym. J. 2011, 47, 1402-1409.

65. Zhang, L.; Luo, J.; Menkhaus, T.J.; Varadaraju, H.; Sun, Y.; Fong, H. Antimicrobial nano-fibrous membranes developed from electrospun polyacrylonitrile nanofibers. J. Membr. Sci. 2011, 369, 499-505.

66. Wang, R.; Liu, Y.; Li, B.; Hsiao, B.S.; Chu, B. Electrospun nanofibrous membranes for high flux microfiltration. J. Membr. Sci. 2012, 392-393, 167-174.

67. Daels, N.; de Vrieze, S.; Sampers, I.; Decostere, B.; Westbroek, P.; Dumoulin, A.; Dejans, P.; de Clerck, K.; van Hulle, S.W.H. Potential of a functionalised nanofibre microfiltration membrane as an antibacterial water filter. Desalination 2011, 275, 285-290.

68. Montazer, M.; Malekzadeh, S.B. Electrospun antibacterial nylon nanofibers through in situ synthesis of nanosilver: Preparation and characteristics. J. Polym. Res. 2012, 19, 9980:1-9980:6.

69. Pant, B.; Pant, H.R.; Pandeya, D.R.; Panthi, G.; Nam, K.T.; Hong, S.T.; Kim, C.S.; Kim, H.Y. Characterization and antibacterial properties of Ag NPs loaded nylon-6 nanocomposite prepared by one-step electrospinning process. Colloid Surfaces A Physicochem. Eng. 2012, 395, 94-99.

70. Mahapatra, A.; Grag, N.; Nayak, B.P.; Mishra, B.G.; Hota, G. Studies on the synthesis of electrospun PAN-Ag composite nanofibers for antibacterial application. J. Appl. Polym. Sci. 2012, 124, 1178-1185.

71. Wang, X.; Chen, X.; Yoon, K.; Fang, D.; Hsiao, B.S.; Chu, B. High flux filtration medium based on nanofibrous substrate with hydrophilic nanocomposite coating. Environ. Sci. Technol. 2005, 39, 7684-7691.

72. Wang, X.; Fang, D.; Yoon, K.; Hsiao, B.S.; Chu, B. High performance ultrafiltration composite membranes based on poly (vinyl alcohol) hydrogel coating on crosslinked nanofibrous poly(vinyl alcohol) scaffold. J. Membr. Sci. 2006, 278, 261-268.

73. Yoon, K.; Kim, K.; Wang, X.; Fang, D.; Hsiao, B.S.; Chu, B. High flux ultrafiltration membranes based on electrospun nanofibrous PAN scaffolds and chitosan coating. Polymer 2006, 47, 2434-2441. 
74. Kaur, S.; Sundarrajan, S.; Rana, D.; Matsuura, T.; Ramakrishna, S. Influence of electrospun fiber size on the separation efficiency of thin film nanofiltration composite membrane. J. Membr. Sci. 2012, 392, 101-111.

75. Feng, C.; Khulbe, K.C.; Matsuura, T.; Gopal, R.; Kaur, S.; Ramakrishna, S.; Khayet, M. Production of drinking water from saline water by air-gap membrane distillation using polyvinylidene fluoride nanofiber membrane. J. Membr. Sci. 2008, 311, 1-6.

76. Wang, G.; Pan, C.; Wang, L.; Dong, Q.; Yu, C.; Zhao, Z.; Qiu, J. Activated carbon nanofiber webs made by electrospinning for capacitive deionization. Electrochim. Acta 2012, 69, 65-70.

77. Kaur, S.; Sundarrajan, S.; Gopal, R.; Ramakrishna, S. Formation and characterization of polyamide composite electrospun nanofibrous membranes for salt separation. J. Appl. Polym. Sci. 2012, 124, E205-E215.

78. Qin, X.-H.; Wang, S.-Y. Electrospun nanofibers from crosslinked poly(vinyl alcohol) and its filtration efficiency. J. Appl. Polym. Sci. 2008, 109, 951-956.

79. Homaeigohar, S.S.; Buhr, K.; Ebert, K. Polyethersulfone electrospun nanofibrous composite membrane for liquid filtration. J. Membr. Sci. 2010, 365, 68-77.

80. Cao, X.; Huang, M.; Ding, B.; Yu, J.; Sun, G. Robust polyacrylonitrile nanofibrous membrane reinforced with jute cellulose nanowhiskers for water purification. Desalination 2013, 361, $120-126$.

(C) 2013 by the authors; licensce MDPI, Basel, Switzerland. This article is an open access article distributed under the terms and conditions of the Creative Commons Attribution license (http://creativecommons.org/licenses/by/3.0/). 